\title{
Fluorescence Probe Based on Graphene Quantum Dots for Selective, Sensitive and Visualized Detection of Formaldehyde in Food
}

\author{
Yanpeng Zhang ${ }^{1}$, Junjie Qi ${ }^{1, *}$, , Mengying $\mathrm{Li}^{1}{ }^{1}$, Dong Gao ${ }^{2}$ and Chengfen Xing ${ }^{2}$ \\ 1 National-Local Joint Engineering Laboratory for Energy Conservation in Chemical Process Integration and \\ Resources Utilization, School of Chemical Engineering and Technology, Hebei University of Technology, \\ Tianjin 300131, China; zhangyanpeng444@163.com (Y.Z.); limengying1520@163.com (M.L.) \\ 2 Key Laboratory of Hebei Province for Molecular Biophysics, Institute of Biophysics, Hebei University of \\ Technology, Tianjin 300401, China; gaodong@iccas.ac.cn (D.G.); xingc@hebut.edu.cn (C.X.) \\ * Correspondence: qijunjie@hebut.edu.cn; Tel./Fax: +86-22-6043-5642
}

check for updates

Citation: Zhang, Y.; Qi, J.; Li, M.; Gao, D.; Xing, C. Fluorescence Probe Based on Graphene Quantum Dots for Selective, Sensitive and Visualized Detection of Formaldehyde in Food. Sustainability 2021, 13, 5273 .

https://doi.org/10.3390/su13095273

Academic Editor: Dario Donno

Received: 1 April 2021

Accepted: 4 May 2021

Published: 8 May 2021

Publisher's Note: MDPI stays neutral with regard to jurisdictional claims in published maps and institutional affiliations.

Copyright: (c) 2021 by the authors. Licensee MDPI, Basel, Switzerland. This article is an open access article distributed under the terms and conditions of the Creative Commons Attribution (CC BY) license (https:// creativecommons.org/licenses/by/ $4.0 /)$.

\begin{abstract}
Graphene quantum dots (GQDs) have been successfully used as a highly sensitive probe for the sensing of formaldehyde ( $\mathrm{HCHO})$ in an aqueous solution. Through static quenching, the probe utilizes the interaction between $\mathrm{HCHO}$ and GQDs to trigger the "turn off" fluorescence response, and has good selectivity. The probe can detect $\mathrm{HCHO}$ in a pure aqueous solution, and it also can still detect $\mathrm{HCHO}$ in a complex environment with a $\mathrm{pH}$ range from 4 to 10 . The concentration of $\mathrm{HCHO}$ and the fluorescence intensity of GQDs show a good linear relationship within the range of $\mathrm{HCHO}$ of $0-1 \mu \mathrm{g} / \mathrm{mL}$, which was much more sensitive than previous reports. The limit of HCHO detection by GQDs is about $0.0515 \mu \mathrm{g} / \mathrm{mL}$. In addition, we successfully applied it to the actual food inspection. It is proved to be a selective, sensitive and visualized method to check whether the concentration of $\mathrm{HCHO}$ in the foods exceeds the regulatory limit, which presents a potential application in food safety testing.
\end{abstract}

Keywords: graphene quantum dots (GQDs); formaldehyde (HCHO); fluorescence probe

\section{Introduction}

Formaldehyde, as the simplest carbonyl compound, is widely used in our daily lives. Due to its antiseptic and bactericidal properties, formaldehyde is often added to foods to keep them fresh. However, excessive intake of formaldehyde is extremely harmful to the human body. As early as 2009, formaldehyde was included in the list of carcinogens by the International Agency for Research on Cancer (IARC) due to its strong pathogenicity for nasopharyngeal carcinoma and weak pathogenicity for leukemia [1]. Therefore, it is extremely important to detect formaldehyde in food with high sensitivity. At present, the detection methods of formaldehyde mainly include spectrophotometry [2], gas chromatography [3], high-performance liquid chromatography [4], Raman spectroscopy [5], mass spectrometry [6] and fluorescence spectrophotometry [7]. In recent years, fluorescence detection technology has received more and more attention due to its simple measurement, high sensitivity, and strong specificity. Specifically, reactive fluorescent probes have been developed [7-9]. The detection reaction mainly includes the reaction of amino $\left(-\mathrm{NH}_{2}\right)$ [10-12] or hydrazine $\left(-\mathrm{NH}^{\left.-\mathrm{NH}_{2}\right)}[13,14]\right.$ with formaldehyde and the aza-Cope rearrangement reaction [15-18]. However, since most of the reaction molecules cannot be directly dissolved in pure water, the reactions are carried out in non-neutral aqueous solutions or organic solvents [19-21]. This greatly limits their practical applications. Therefore, it is necessary to develop a fluorescent probe that can detect formaldehyde in pure water solvent.

Graphene quantum dots (GQDs), a new type of OD carbon nanomaterial, have attracted more and more attention due to their excellent optical properties, high chemical stability, low environmental hazards and excellent biocompatibility. The preparation of 
GQDs mainly includes "bottom-up" and "top-down" methods [22]. The "bottom-up" method mainly converts non-graphite carbon sources into GQDs through chemical reactions, such as pyrolysis [23-25], microwave [26,27], ultrasonic [28], hydrothermal [29], etc. The "top-down" method mainly uses physical or chemical methods to strip or decompose bulk carbon materials into nano-sized graphene, such as arc discharge [30], laser ablation [31,32], electrochemical oxidation [33,34], chemical cutting [35],, etc. The pyrolysis method mainly controls the degree of carbonization of the substance by controlling the heating time to prepare GQDs. It is widely used because of its simple operation and low preparation cost. As a new type of fluorescent probe, GQDs are widely used in fluorescence detection [36-40], bioimaging [41], drug delivery [42-44], photocatalysis [45-47] and other fields. In recent years, it has also attracted great attention in the development of specific and selective fluorescent sensing probes. Thus far, GQDs have been reported to detect metal ions and organic matter, such as $\mathrm{Fe}^{3+}[25,48-50], \mathrm{Hg}^{2+}$ [50-53], $\mathrm{Cu}^{2+}$ [54], TNT [39] and benzoquinones [36-38,40], etc. The fluorescence of GQDs can be effectively quenched by electron acceptors or electron donors in solution, which indicates that GQDs are excellent electron donors or electron acceptors. This provides the possibility for GQDs to detect formaldehyde. The surface of GQDs contains a large number of carboxyl and hydroxyl groups, which gives it excellent water solubility, so GQDs can be well-dispersed in pure water solvents [55]. It is these excellent properties that make GQDs a competitive substitute for organic fluorescent probes and heavy metal quantum dots.

In this work, we presented a method to accurately detect formaldehyde in pure aqueous solutions using the fluorescence characteristics of GQDs. It has solved the dilemma that $\mathrm{HCHO}$ must be detected in organic solvents or acid-base solutions. Through static quenching, GQDs interact with formaldehyde in the ground state, meaning that formaldehyde can effectively quench the fluorescence of GQDs. The probe can selectively and sensitively detect formaldehyde in the range of $0-1.0 \mu \mathrm{g} / \mathrm{mL}$. In addition, the fluorescence intensity of GQDs in this interval also showed a good linear relationship with the concentration of formaldehyde. Unmodified GQDs can effectively detect formaldehyde in pure water solvents. There is a potential application in the green detection of formaldehyde in aqueous solutions in the future.

\section{Materials and Methods}

\subsection{Materials}

All chemicals used were at least of analytical reagent grade and used without further purification. Citric acid and sodium hydroxide were obtained from Shanghai Aladdin Biotechnology Co., Ltd. (Shanghai, China). Formaldehyde solution and paraffin liquid were purchased from Rhawn of Shanghai Yi en Chemical Reagent Co., Ltd. (Shanghai, China). Ethanol, methanol, acetaldehyde, acetone and phosphoric acid were obtained from Fuchen Chemical Reagent Co., Ltd. (Tianjin, China). Benzene, Toluene, Xylene and ammonia were purchased from Tianjin Kemiou Chemical Reagent Co., Ltd. (Tianjin, China). The water used in all experiments was ultrapure water with a resistivity of $18.2 \mathrm{M} \Omega \cdot \mathrm{cm}$.

\subsection{Synthesis of GQDs}

GQDs were synthesized according to the reported method [23]. In short, we added $2 \mathrm{~g}$ citric acid (CA) to a small sample bottle and put it in an oil bath heated to $200{ }^{\circ} \mathrm{C}$ with a magnetic stirrer. CA changed from a solid state to a colorless liquid state, and then gradually turned yellow. In about thirty minutes, the color of the liquid turned orange. We then added the orange liquid drop wise to $10 \mathrm{mg} / \mathrm{mL} \mathrm{NaOH}$ solution under vigorous stirring. Finally, we adjusted the solution to neutral with a $10 \mathrm{mg} / \mathrm{mL} \mathrm{NaOH}$ solution. The solution of GQDs was obtained and stored in a refrigerator at $4{ }^{\circ} \mathrm{C}$ for use. The characteristic test of GQDs was further purified. Ethanol was added to the GQDs to make the large particles settle, and then dried with a rotary evaporator. The GQDs can be easily redispersed into water. 


\subsection{Characterization}

Fluorescence emission and excitation spectra were recorded on a Hitachi F-4600 fluorescence spectrophotometer. The slit widths of emission and excitation were both $5 \mathrm{~nm}$, and the voltage of PMT was $700 \mathrm{~V}$. Transmission electron microscopy (TEM) images were obtained with a FEI Talos F200S field emission high resolution transmission electron microscope. Atomic force microscope (AFM) images were taken with an Agilent 5500 Atomic force microscope. Fourier transform infrared spectroscopy (FTIR) was conducted using a Bruker Vertex $80 \mathrm{~V}$ Spectrometer. The fluorescence lifetime was recorded on an Edinburgh Instruments FSP920 Fluorescence Spectrometer. Zeta potential was carried out with a Malvern Zetasizer Nano ZEN3600 instrument. UV-Vis absorption spectra were measured on an Analytik Jena Specord 250 plus UV VIS Spectrophotometer.

\subsection{Quantum Yields (QY) Measurements of GQDs}

The fluorescence QY of GQDs were measured by a reference method [56]. Quinine sulfate and GQDs were prepared into solutions with an absorbance value of less than 0.05 , and then diluted into five solutions with different concentrations. We calculated their fluorescence QY by measuring their ultraviolet absorption and fluorescence emission spectra. Calculated according to the following formula, $\mathrm{M}_{\mathrm{x}}$ and $\mathrm{M}_{\mathrm{st}}$ are the slope of the straight line obtained by plotting the integrated area of the fluorescence intensity of GQDs and quinine sulfate and the absorbance value, respectively. $\varphi_{\mathrm{x}}$ and $\varphi_{\text {st }}$ are the QY of GQDs and quinine sulfate, and the value of $\varphi_{s t}$ is $0.54 . \eta_{x}$ and $\eta_{s t}$ are the refractive indices of GQDs and quinine sulfate solutions, and both are 1.33.

$$
\varphi_{\mathrm{x}}=\varphi_{\mathrm{st}}\left(\frac{\mathrm{M}_{\mathrm{x}}}{\mathrm{M}_{\mathrm{st}}}\right)\left(\frac{\eta_{\mathrm{x}}}{\eta_{\mathrm{st}}}\right)^{2}
$$

\subsection{Detection of $\mathrm{HCHO}$}

The detection of $\mathrm{HCHO}$ was carried out by measuring the fluorescence spectra of GQDs in the presence and absence of HCHO. Simply put, we added HCHO of different concentrations to $1 \mathrm{mg} / \mathrm{mL}$ GQDs, then diluted the solution to $0.5 \mathrm{mg} / \mathrm{mL}$ by adding ultrapure water, and allowed the solution to interact at $30^{\circ} \mathrm{C}$ for $8 \mathrm{~h}$. The concentration of $\mathrm{HCHO}$ was detected by the linear relationship between fluorescence intensity of GQDs and concentration of $\mathrm{HCHO}$.

\subsection{Detection of HCHO in Real Food}

The detection of $\mathrm{HCHO}$ in food samples aims to extract $\mathrm{HCHO}$ from the food by steam distillation. In short, we placed $10 \mathrm{~g}$ of meat into a $250 \mathrm{~mL}$ two-necked flask, then added $20 \mathrm{~mL}$ of ultrapure water, $10 \mathrm{~mL}$ of $10 \%$ phosphoric acid, $25 \mathrm{~mL}$ of liquid paraffin, and then used steam distillation to extract $200 \mathrm{~mL}$ of distillate. An equal volume of extract was added to $1 \mathrm{mg} / \mathrm{mL}$ GQDs (contaminated sample is $4 \mu \mathrm{g} / \mathrm{mL} \mathrm{HCHO}$ was added to the extract), and the fluorescence intensity of GQDs was measured at $30^{\circ} \mathrm{C}$ for $8 \mathrm{~h}$ to determine the content of $\mathrm{HCHO}$ in food. Fluorescent test paper detects $\mathrm{HCHO}$ in real samples by placing $2 \mathrm{~g}$ of normal samples or contaminated samples into Petri dishes with GQDs fluorescent test paper. $\mathrm{HCHO}$ in contaminated food will transfer from the food to the GQDs fluorescent test paper through volatilization. GQDs fluorescent test paper was prepared by soaking non-fluorescent test paper through GQDs and then drying. Food with excessive $\mathrm{HCHO}$ was made by soaking the meat in $1 \mathrm{mg} / \mathrm{mL} \mathrm{HCHO}$ for $10 \mathrm{~min}$. The detection of $\mathrm{HCHO}$ in food extract and the GQDs fluorescent test paper to detect $\mathrm{HCHO}$ in real food were repeated three times or more.

\section{Results and Discussion}

\subsection{Principle of GQDs Detecting $\mathrm{HCHO}$}

Scheme 1 shows a schematic diagram of GQDs detecting HCHO. GQDs can emit bright cyan fluorescence under the irradiation of ultraviolet light, and after interacting with 
$\mathrm{HCHO}$, the fluorescence of GQDs is quenched. In foods with excessive HCHO content, $\mathrm{HCHO}$ transfers to the test paper through volatilization and quenches the fluorescence of GQDs. GQDs fluorescent test paper does not emit fluorescence, while GQDs fluorescent test paper in normal food still emits bright cyan fluorescence.

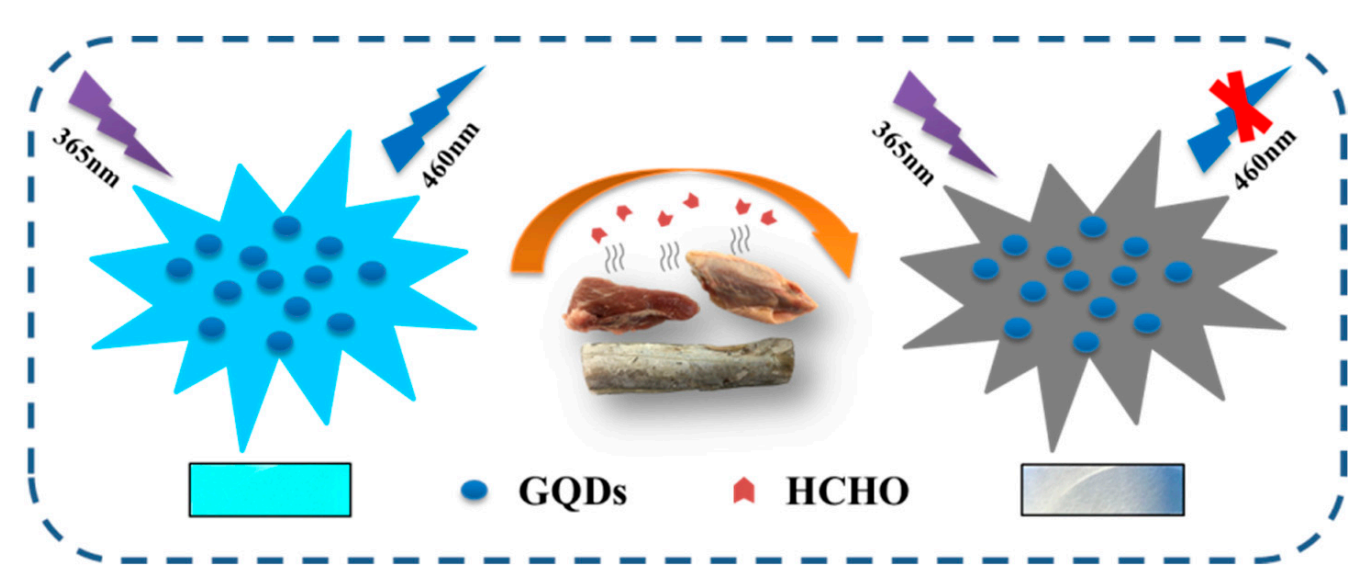

Scheme 1. Schematic representation of GQDs fluorescence detection HCHO, and the sizes of GQDs and $\mathrm{HCHO}$ are not drawn to scale.

\subsection{Structure and Character of GQDs}

To investigate the structure of GQDs, TEM and AFM were performed. It can be observed from the TEM image that GQDs are nanoparticles distributed almost in a circular shape. The inset (left) of the TEM image shows that these GQDs are uniform in size, ranging from 12 to $18 \mathrm{~nm}$ in diameter. Figure S1 is the TEM image of GQDs at a scale bar of $200 \mathrm{~nm}$, which also shows that GQDs are uniformly dispersed nanosheets with a size of approximately $15 \mathrm{~nm}$. Additionally, the size distribution of GQDs was also measured by dynamic light scattering in aqueous solution, which proved that the size of GQDs is between 12 and $30 \mathrm{~nm}$, which is consistent with the TEM data (Figure S2). The highresolution TEM (HRTEM) observation of the GQDs. Figure 1a inset (right) reveals the crystallinity of the GQDs, the labelled interplanar distance is $0.25 \mathrm{~nm}$. AFM results show that the height of GQDs (Figure 1b) is mainly distributed in the range of $2 \sim 3 \mathrm{~nm}$, similar to the height observed when approximately two to three layers are formed in graphene [52]. In addition, the zeta potential of GQDs was measured to be $-9.2 \mathrm{mV}$ (Table S1), confirming that the surface is negatively charged, which is related to the negatively charged carboxyl groups on the surface of GQDs. Figure S3 is the UV absorption graph of GQDs. It can be seen from the figure that GQDs have a strong absorption before $320 \mathrm{~nm}$, which is similar to the UV absorption of graphene. GQDs has an ultraviolet absorption peak at $355 \mathrm{~nm}$, and it is caused by $n-\pi^{*}$ transition of the $C=O$ bond [57]. This feature shows that GQDs can be excited by widely used ultraviolet lamps, which is very convenient for application.

The fluorescence emission spectra of the GQDs solution are depicted in Figure 1c. GQDs revealed fluorescence properties, as shown by the apparent absorption band at $366 \mathrm{~nm}$, corresponding to the excitation spectra and displayed the fluorescence intensity (maximum emission) at $460 \mathrm{~nm}$. The inset of Figure 1c is a digital photograph of the GQDs aqueous solution under day light (vis) and a $365 \mathrm{~nm}$ UV lamp. It is clearly observed that the GQDs sample shows a homogeneous dispersion in aqueous solution at room temperature and is highly stable. The GQDs solution at a low concentration $(0.5 \mathrm{mg} / \mathrm{mL})$ is colorless under visible light, and emits bright cyan fluorescence under ultraviolet light irradiation. Based on fluorescence spectral results, it is also inferred that CA polymerization changed the material structure to attain fluorescence characteristics. By selecting quinine sulfate as the standard, the fluorescence QY of GQDs at $366 \mathrm{~nm}$ were calculated to be about $8.57 \%(8.13 \sim 9.05 \%)$ (Tables S2 and S3, Figure S4), which is consistent with previous related literature [23]. Figure S5 is the stability of GQDs fluorescence intensity over time at $4{ }^{\circ} \mathrm{C}$. 
The fluorescence intensity of GQDs gradually decreased over time, but it only dropped $15 \%$ in a week, indicating that the fluorescence of GQDs was very stable.
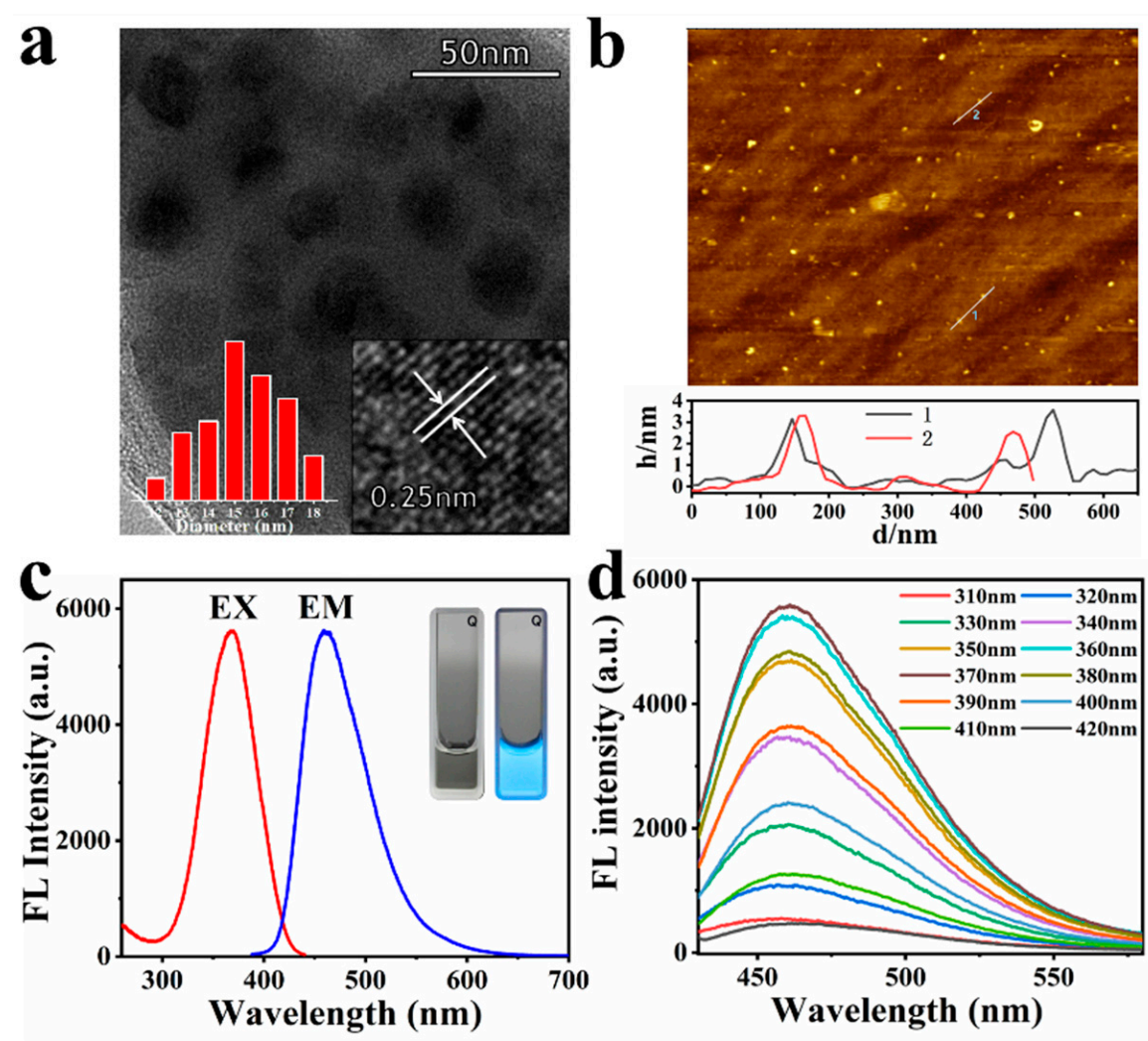

Figure 1. (a) TEM images of GQDs. Inset: HR-TEM (right) and particle size distribution (left); (b) AFM image of the GQDs, line through some of the GQDs shows the height profile; (c) maximum excitation and emission of fluorescence spectra of the GQDs. Inset: photographs of the solution of GQDs taken under day light (left) and under UV light (right); (d) emission spectra of the GQDs with the excitation of different wavelengths.

The fluorescence spectra of GQDs of different excitation wavelengths are shown in Figure 1d. The fluorescence of GQDs shows a slight correlation with the excitation wavelength, as with most carbon-based nanomaterials. With the increase in the excitation wavelength, the maximum value of the fluorescence emission peak of GQDs gradually shifts to the long wavelength direction. This may be caused by the surface defect state near the Fermi level of these carbon-based fluorescent nanomaterials $[54,58]$. However, it can be seen from Figure $1 \mathrm{~d}$ that the maximum emission peak of GQDs is barely affected by the change in excitation wavelength. The excitation wavelength is from 320 to $410 \mathrm{~nm}$, and the maximum emission wavelength of GQDs shifts from 457 to $463 \mathrm{~nm}$. Additionally, this property shows that even if an ordinary UV lamp is used as the excitation light source, accurate detection data can be obtained.

The functional groups of the GQDs were confirmed by using FTIR (Figure S6). The band at $3430 \mathrm{~cm}^{-1}$ is assigned to stretching vibrations of -OH. Furthermore, the bands at $1700 \mathrm{~cm}^{-1}$ are from the stretching vibration of $\mathrm{C}=\mathrm{O}$. A peak related to $\mathrm{C}-\mathrm{O}$ stretching vibration of the carboxyl group is at $1296 \mathrm{~cm}^{-1}$. The peak at $933 \mathrm{~cm}^{-1}$ is associated with the bending vibration of -OH. It indicates that there are lots of hydroxyl groups and carboxyl group on the surface of GQDs. It also explains why GQDs have good hydrophilic properties. The absorption peak at $1390 \mathrm{~cm}^{-1}$ is due to in-plane bending vibration of C-H. The bands at 2979 and $2920 \mathrm{~cm}^{-1}$ are attributed to the absorption band of $-\mathrm{CH}_{3}$ and $-\mathrm{CH}_{2}$ of antisymmetric stretching vibration. An aromatic $\mathrm{C}=\mathrm{C}$ stretching vibration peak is observed at $1580 \mathrm{~cm}^{-1}$, which indicates the dehydration of CA to GQDs [23,26,52]. 


\subsection{Ability of GQDs to Detect HCHO}

GQDs have been increasingly used in the selective detection of luminescence species. The functional groups on the surface of GQDs play an important role in the fluorescence detection of organic compounds and ions. In this work, we found that $\mathrm{HCHO}$ has a strong quenching effect on GQDs. As shown in Figure 2a, when a certain amount of HCHO is added, the fluorescence intensity of GQDs will decrease to a certain extent. With the increase in $\mathrm{HCHO}$ concentration, the fluorescence quenching of GQDs becomes more obvious. Therefore, we can use GQDs as fluorescent probes to detect HCHO. In order to ensure that the detection result is not affected by the inner-filter effect of fluorescence and is more accurate, we tested the fluorescence intensity of different concentrations of GQDs in aqueous solution. From Figure S7, we can see that as the concentration of GQDs increases, the fluorescence intensity of GQDs gradually increases. Due to the influence of the innerfilter effect of fluorescence, when the concentration of GQDs is greater than $0.05 \mathrm{mg} / \mathrm{mL}$, the rate of increase in the fluorescence intensity of GQDs decreases significantly. Finally, we decided to use $0.5 \mathrm{mg} / \mathrm{mL}$ GQDs aqueous solution to detect HCHO. In addition, in order to perform the test in a more real environment, the temperature is set at $30^{\circ} \mathrm{C}$.
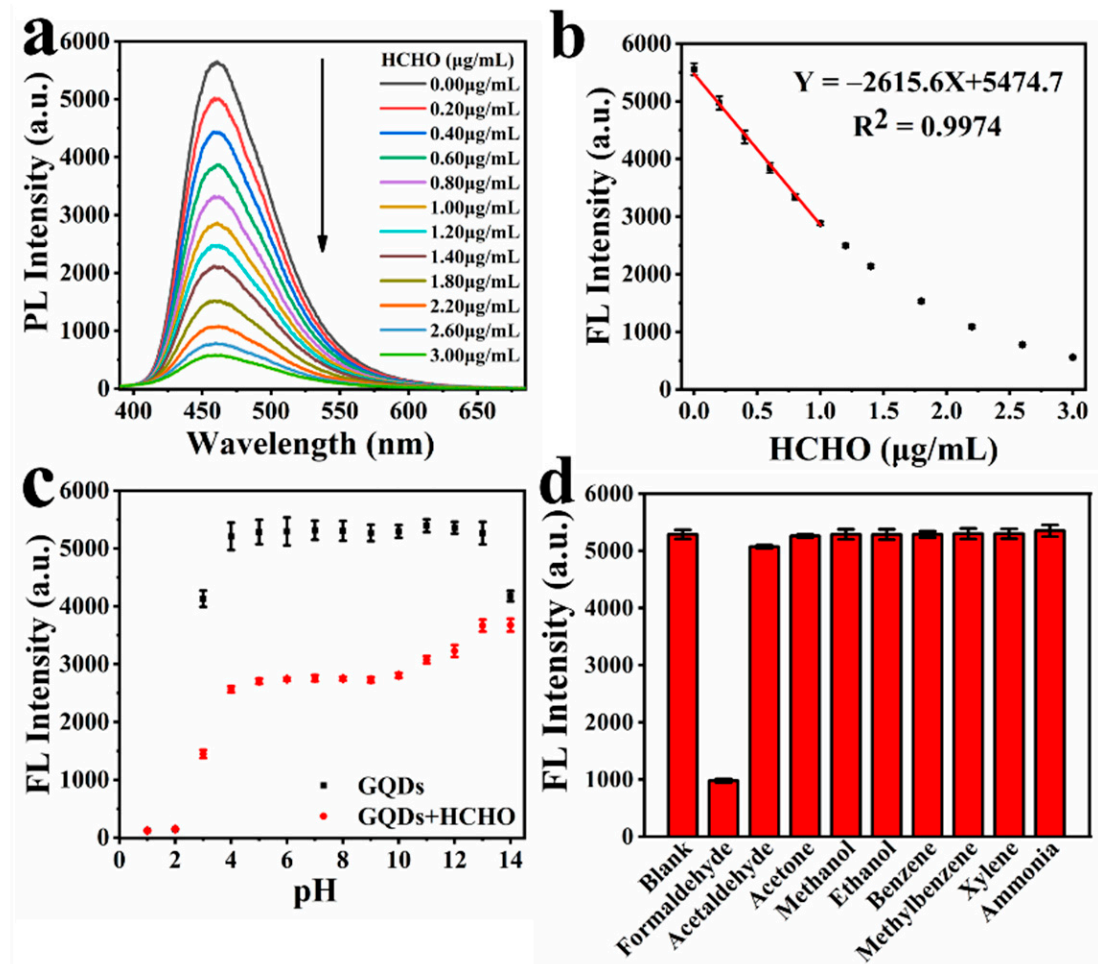

Figure 2. (a) Fluorescence emission spectra of GQDs in the presence of different concentrations of $\mathrm{HCHO}$; (b) the linear relationship between the fluorescence intensity of GQDs and concentration of $\mathrm{HCHO}$; (c) fluorescence intensity of aqueous solution of GQDs and the ability detect to $\mathrm{HCHO}$ of GQDs in different $\mathrm{pH}$; (d) the selectivity of GQDs detection of $\mathrm{HCHO}$ by fluorescence.

The interaction time between HCHO and GQDs is shown in Figure S8; $2 \mu \mathrm{g} / \mathrm{mL}$ of $\mathrm{HCHO}$ was added to the GQDs solution. As the interaction time increases, the fluorescence intensity of GQDs continues to decrease, and the decrease becomes slower and slower with the increase in time. The rate of change in fluorescence intensity is already very low when the interaction progresses to $8 \mathrm{~h}$. Therefore, the concentration of $\mathrm{HCHO}$ can be determined by measuring the fluorescence intensity of GQDs at $8 \mathrm{~h}$ of this interaction. The effect of different concentrations of $\mathrm{HCHO}$ on the fluorescence intensity of GQDs is shown in Figure 2a. As the concentration of $\mathrm{HCHO}$ increases, the fluorescence intensity of GQDs continues to decrease. Figure $2 \mathrm{~b}$ shows that in the range of $\mathrm{HCHO}$ concentration of $0-1 \mu \mathrm{g} / \mathrm{mL}$, 
there is a good linear relationship between the fluorescence intensity of GQDs and the concentration of $\mathrm{HCHO}$ - the linear regression equation was $\mathrm{Y}=-2281.82 \mathrm{X}+5249.77$, with a correlation coefficient $\mathrm{R}^{2}=0.98685$. Additionally, the theoretical limit of detection (LOD) of our sensor was calculated to be about $0.0515 \mu \mathrm{g} / \mathrm{mL}$, according to the extensive accepted method [59]. This probe can be comparable with many reported fluorescent probes (Table S4).

$$
\mathrm{LOD}=3 \sigma / \mathrm{s}=3 \times 39.17 / 2281.82=0.0515 \mu \mathrm{g} / \mathrm{mL}
$$

where $\sigma$ is the standard deviation of the corrected blank signals of the GQDs and $\mathrm{s}$ is the slope of the calibration curve.

In order to study the application range of fluorescence detection of $\mathrm{HCHO}$, we tested the fluorescence intensity of GQDs under different $\mathrm{pH}$ conditions, and the fluorescence intensity of GQDs after interacting with $\mathrm{HCHO}$ under different $\mathrm{pH}$ conditions. The result is shown in Figure 2c. Under alkaline conditions, the fluorescence intensity of GQDs decreased significantly only at $\mathrm{pH}=14$, but the effect of GQDs' detection of $\mathrm{HCHO}$ by fluorescence at the range of $\mathrm{pH}=11-14$ decreased significantly as the alkalinity increased. Under acidic conditions, the fluorescence intensity of GQDs and GQDs after interacting with $\mathrm{HCHO}$ both dropped significantly at $\mathrm{pH}=3$. Additionally, when the $\mathrm{pH} \leq 2$, the fluorescence of GQDs was completely quenched by $\mathrm{H}^{+}$, GQDs were no longer able to detect $\mathrm{HCHO}$ as a fluorescent probe. In general, the fluorescence intensity of GQDs is very stable in the range of $\mathrm{pH}=4-13$, and GQDs can accurately detect HCHO by means of fluorescence in the range of $\mathrm{pH} 4-10$. This shows that GQDs can detect $\mathrm{HCHO}$ in a wide $\mathrm{pH}$ range.

Selectivity is a very important parameter to evaluate the performance of a new fluorescence probe. As shown in Figure 2, we measured the effects of common substances and substances similar in structure to $\mathrm{HCHO}$ on the fluorescence intensity of GQDs. The fluorescence of the GQDs solution was obviously quenched by $\mathrm{HCHO}$. Acetaldehyde has a slight effect on the fluorescence of GQDs due to its structure being very similar to $\mathrm{HCHO}$, but its fluorescence quenching effect on GQDs is less than 5\%, and will not affect the detection of HCHO by GQDs. Other substances have no quenching effect on the fluorescence of GQDs. This indicates the GQD fluorescent probe has good selectivity to $\mathrm{HCHO}$.

\subsection{Mechanism of GQDS Detects of $\mathrm{HCHO}$}

In order to verify the mechanism of fluorescence quenching by $\mathrm{HCHO}$, we comparing the FTIR spectra of GQDs before and after the interaction with $\mathrm{HCHO}$, explain the changes in the surface functional groups of GQDs (Figure S6). We found that the stretching vibration absorption peak of C-O-C at $1130 \mathrm{~cm}^{-1}$ is significantly enhanced. Additionally, the C-O at $1000 \mathrm{~cm}^{-1}$ and the $-\mathrm{OH}$ stretching vibration at $933 \mathrm{~cm}^{-1}$ also increased. In addition, we also found that the $\mathrm{C}-\mathrm{O}$ stretching vibration absorption peak of the carboxyl group at $1296 \mathrm{~cm}^{-1}$ slightly weakened. This suggests that $\mathrm{HCHO}$ has interacted with the groups on the surface of GQDs. It can be seen from Table S1 that after the interaction of GQDs with $\mathrm{HCHO}$, the zeta potential of GQDs changed from -9.20 to $-4.55 \mathrm{mV}$, indicating that the negatively charged groups on the surface of GQDs decreased. It also proved that the groups on the surface of GQDs changed. Additionally, the UV-Vis absorption spectra of aqueous solutions of GQDs in the presence of different concentrations of HCHO indicate that the maximum absorption peak decreases with the increase in HCHO concentration (Figure 3a). Additionally, the absorption peak has a clear blue shift. This implies that GQDs are consumed in the interaction with HCHO. The PL lifetime decay of GQDs shows a single exponential function, which is 1.51 ns. Additionally, the PL lifetime decay of GQDs after interaction with $\mathrm{HCHO}(1 \mu \mathrm{g} / \mathrm{mL})$ is $1.55 \mathrm{~ns}$ (Figure $3 \mathrm{~b}$ ). The PL lifetime of GQDs before and after interaction with $\mathrm{HCHO}$ has hardly changed. This also implies that $\mathrm{HCHO}$ interacts with GQDs to generate non-luminescent ground state complexes, and the interaction is static quenching. 

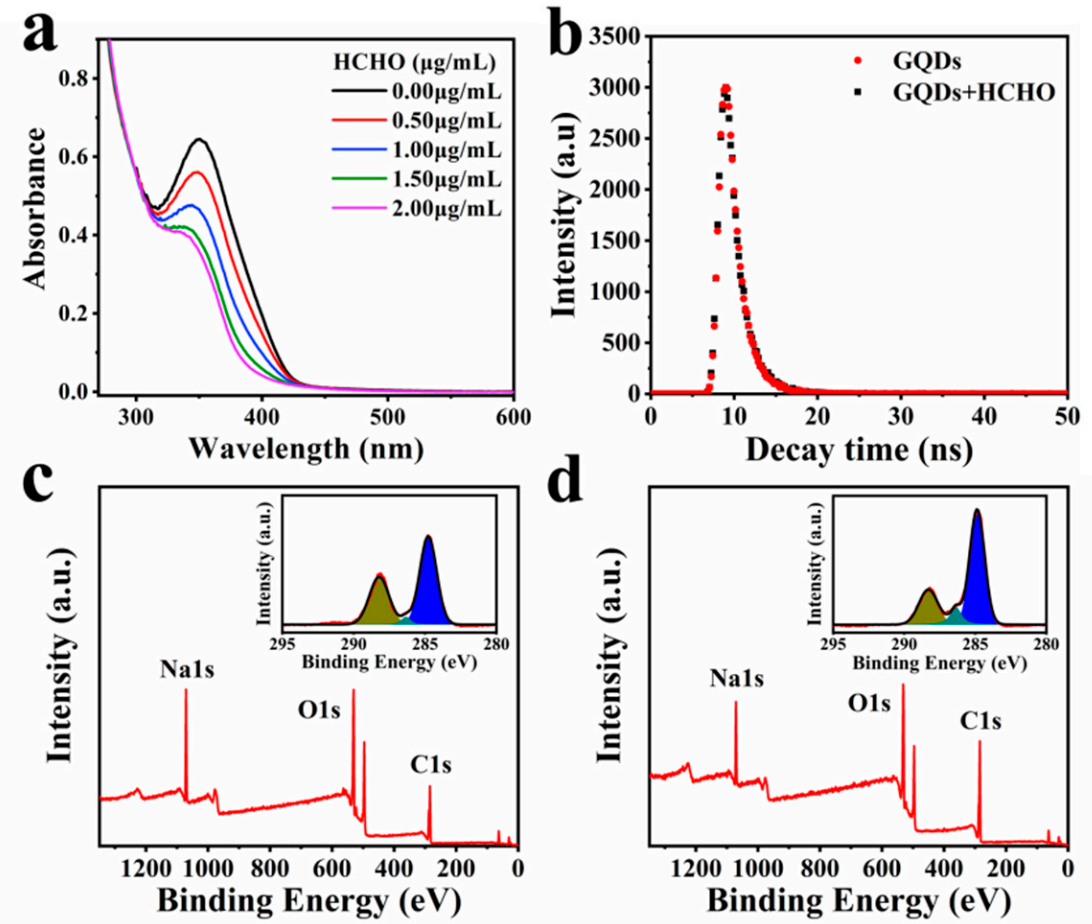

Figure 3. (a) UV-Vis absorption spectra of GQDs interacted with different concentrations of HCHO $(0-2 \mu \mathrm{g} / \mathrm{mL})$; (b) PL decay of GQDs before and after interaction with $\mathrm{HCHO}$; (c) XPS full scan survey of GQDs. Inset panels show the high-resolution C1s spectra; (d) XPS full scan survey of GQDs after interaction with $\mathrm{HCHO}$. Inset panels show the high-resolution $\mathrm{C} 1 \mathrm{~s}$ spectra.

The surface chemical composition was explored by XPS analysis. In full scan XPS spectra of GQDs before and after the interaction with HCHO (Figure 3c,d), they show strong signals of C1s $(284.13 \mathrm{eV}), \mathrm{O} 1 \mathrm{~s}(530.31 \mathrm{eV})$ and Na1s $(1075.00 \mathrm{eV})$ peaks. After GQDs interacted with $\mathrm{HCHO}$, the Na peak intensity became weaker. The decrease in $\mathrm{Na}$ indicates the decrease in carboxyl content on the surface of GQDs, which is similar to the result of FTIR spectra. The peak intensity ratios of O1s/C1s $\left(\mathrm{R}_{\mathrm{O} / \mathrm{C}}\right)$ were calculated from full survey XPS spectra. The $\mathrm{R}_{\mathrm{O} / \mathrm{C}}$ decreased from 0.734 to 0.497 . This indicates that oxygen content in GQDs is largely reduced by HCHO. In the illustration of Figure $3 \mathrm{c}, \mathrm{d}$, the high-resolution C1s XPS spectra can be fitted into three gaussian peaks at 284.5, 286.1 and $288.6 \mathrm{eV}$, which correspond to the $\mathrm{sp}^{2}$ carbon $(\mathrm{C}-\mathrm{C} / \mathrm{C}=\mathrm{C})$ in graphene, the sp3 carbon $(\mathrm{C}-\mathrm{O})$, and the $\mathrm{C}=\mathrm{O}$. It can be seen from Figure $3 \mathrm{c}, \mathrm{d}$ that the peaks at $288.6 \mathrm{eV}$ have a significant decrease compared with before the interaction. Correspondingly, the peaks at 284.5 and $286.1 \mathrm{eV}$ were enhanced. This means that the content of $\mathrm{C}=\mathrm{O}$ was reduced, but the sp2 and sp3 carbon appeared to increase. It also implies that the groups on the surface of GQDs were changed. Figure S9 shows the $\mathrm{pH}$ of GQDs after interacting with different concentrations of $\mathrm{HCHO}(0-2.0 \mu \mathrm{g} / \mathrm{mL})$. The results show that the $\mathrm{pH}$ of GQDs did not change with the addition of $\mathrm{HCHO}$, suggesting that the carboxyl groups on the surface of GQDs did not interact with HCHO. Figure S10 shows the Raman spectra of GQDs before and after the interaction with HCHO. Since the D peak of GQDs is too weak, we roughly compared the $\mathrm{I}_{\mathrm{D}} / \mathrm{I}_{\mathrm{G}}$ of GQDs before and after the interaction with $\mathrm{HCHO}$. After GQDs interacted with $\mathrm{HCHO}$, the $\mathrm{I}_{\mathrm{D}} / \mathrm{I}_{\mathrm{G}}$ value changed from 0.295 to 1.05 , indicating that sp3 carbon increased, which was consistent with the XPS data. The PL lifetime decay, UV-Vis absorption spectra, XPS and Raman spectra together intimate that the quenching mechanism of $\mathrm{HCHO}$ to GQDs is static quenching. 


\subsection{Detection of HCHO in Actual Food}

To evaluate the applicability of the GQDs fluorescence probe, the performance of GQDs in three common meat samples (pork, chicken and hairtail) was investigated. HCHO in food samples is extracted by steam extraction. As can be seen from the image (Figure $4 b$ ), the extracts of the three foods basically did not quench the fluorescence of GQDs. However, the $\mathrm{HCHO}$ content in hairtail is slightly higher, compared with pork and chicken. We can see that the concentration of $\mathrm{HCHO}$ in hairtail is obviously less than $0.2 \mu \mathrm{g} / \mathrm{mL}$, which means that the $\mathrm{HCHO}$ content in hairtail is less than $8 \mathrm{mg} / \mathrm{kg}$, which is within the safe range. When $2 \mu \mathrm{g} / \mathrm{mL}$ of $\mathrm{HCHO}$ was added to water and three food extracts, all solutions showed an equal drop. Quite good consistency was obtained, demonstrating that the matrix effect of these water and food samples is negligible.
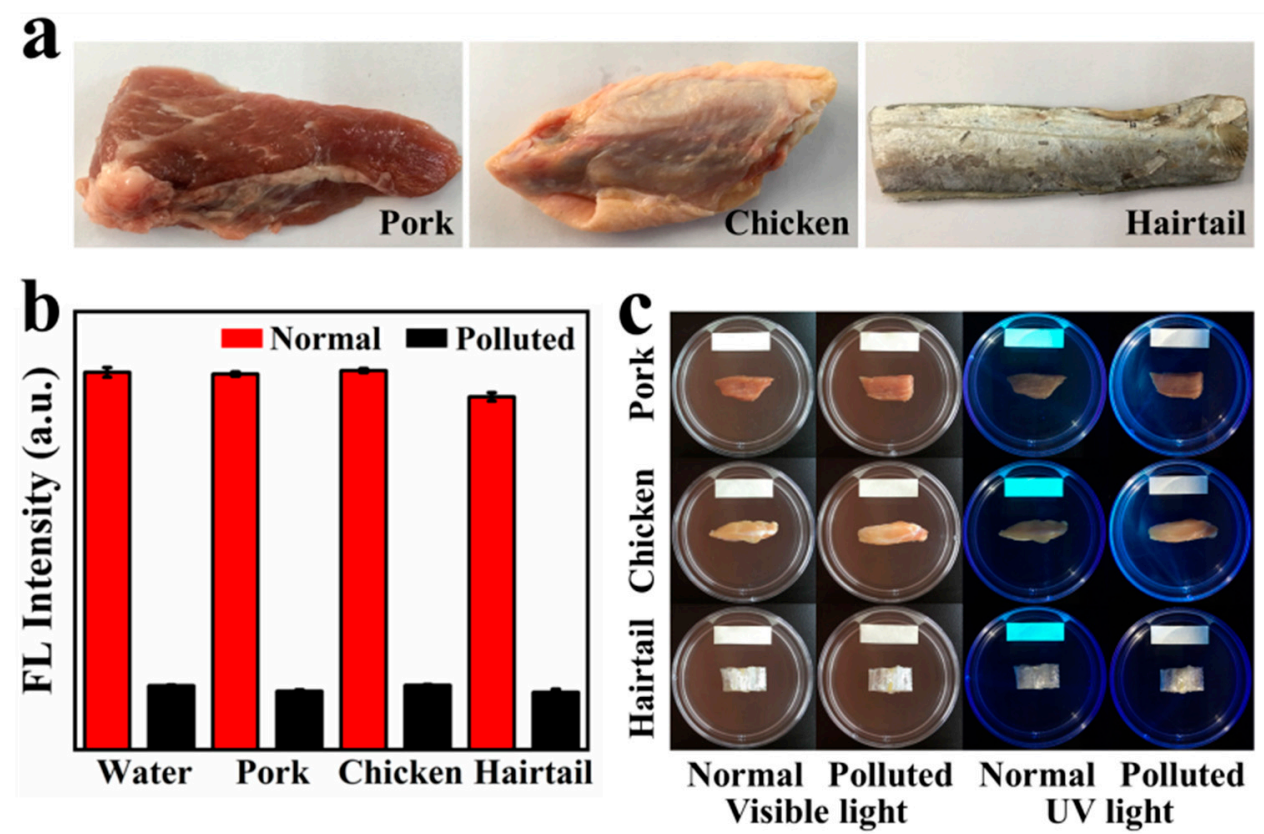

Figure 4. (a) Photos of these real-world foods: pork, chicken and hairtail (purchased from the supermarket nearby); (b) fluorescence intensity of GQDs at $366 \mathrm{~nm}$ for three commercially available food extracts and water (normal and polluted); (c) detection of the content of HCHO in three foods (normal and polluted) by GQDs fluorescent test paper.

In addition, we made GQDs into test papers in order to further facilitate the application. Use test paper to quickly detect whether $\mathrm{HCHO}$ is added to food. Foods immersed in a $\mathrm{HCHO}$ solution usually have higher $\mathrm{HCHO}$ content than the detection range of GQDs. Therefore, at room temperature, the fluorescence of GQDs can be quenched by $\mathrm{HCHO}$ volatilized in the food in a short time. As shown in Figure 4c, the GQDs test paper in the normal sample emits cyan fluorescence under the irradiation of an ultraviolet lamp, and the fluorescence is not quenched. In the contaminated sample, through volatilization, $\mathrm{HCHO}$ is transferred from the food to the GQDs fluorescent test paper, quenching the cyan fluorescence of GQDs. Therefore, GQDs fluorescent test paper no longer emits cyan fluorescence. Preliminary experiments show that GQDs have great potential in making fluorescent test paper of $\mathrm{HCHO}$. These results are quite encouraging, suggesting the potentially wide and practical application of the GQDs sensor.

\section{Conclusions}

In this work, we have proposed a method to detect $\mathrm{HCHO}$ in pure water solvent through a GQDs fluorescent probe. The detection of $\mathrm{HCHO}$ is based on static quenching to achieve the effect of fluorescence "turn-off". GQDs have been proven to have high sensitivity to trace $\mathrm{HCHO}(0-3 \mu \mathrm{g} / \mathrm{mL})$ in aqueous solution, and the $\mathrm{HCHO}$ concentration 
has a very good linear relationship with the fluorescence intensity of GQDs within the $\mathrm{HCHO}$ concentration range of $0-1 \mu \mathrm{g} / \mathrm{mL}$. In particular, it can quantitatively analyze the $\mathrm{HCHO}$ concentration in many food and water samples in the real world. We have also prepared a GQDs fluorescent test paper to visually detect $\mathrm{HCHO}$ in foods, which shows that it has great potential practical application value.

Supplementary Materials: The following are available online at https:/ /www.mdpi.com/article/ 10.3390/su13095273/s1, Figure S1. The TEM images of GQDs, Figure S2. The size distribution of GQDs was measured by dynamic light scattering in aqueous solution, Figure S3. UV-Vis absorption spectrum GQDs, Table S1: The zeta potential of GQDs before and after the interaction with HCHO, Table S2: UV absorption and its corresponding fluorescence spectrum integral area of quinine sulfate, Table S3: UV absorption and its corresponding fluorescence spectrum integral area of GQDs, Figure S4: (a) The relationship of fluorescence spectrum integral area of GQDs and its absorption; (b) the relationship of fluorescence spectrum integral area of quinine sulfate and its absorption, Figure S5. The stability of GQDs fluorescence intensity over time at $4{ }^{\circ} \mathrm{C}$, Figure S6: FTIR of GQDs before and after the interaction with $\mathrm{HCHO}$, Figure S7: Fluorescence intensity of different concentrations of GQDs, Figure S8: The interaction time of HCHO and GQDs, Table S4. The comparison of the detection limit and linear range of our probe and some existed ones, Figure S9. The $\mathrm{pH}$ of GQDs after interacted with different concentrations of $\mathrm{HCHO}$, Figure S10. The Raman spectrum of GQDs before and after the interaction with $\mathrm{HCHO}$.

Author Contributions: J.Q. and C.X. designed experiments and organized the manuscript; Y.Z. performed experimental part and analyzed data; M.L. performed experimental part; D.G. analyzed data. All authors have read and agreed to the published version of the manuscript.

Funding: This research was funded by the Natural Science Foundation of Hebei Province, grant number E2015202073.

Acknowledgments: The authors are grateful for the financial support of the Natural Science Foundation of Hebei Province.

Conflicts of Interest: The authors declare no conflict of interest.

\section{References}

1. Baan, R.; Grosse, Y.; Straif, K.; Secretan, B.; El Ghissassi, F.; Bouvard, V.; Benbrahim-Tallaa, L.; Guha, N.; Freeman, C.; Galichet, L.; et al. Special Report: Policy A review of human carcinogens-Part F: Chemical agents and related occupations. Lancet Oncol. 2009, 10, 1143-1144. [CrossRef]

2. Li, Q.; Sritharathikhun, P.; Motomizu, S. Development of novel reagent for Hantzsch reaction for the determination of formaldehyde by spectrophotometry and fluorometry. Anal. Sci. 2007, 23, 413-417. [CrossRef] [PubMed]

3. Takeuchi, A.; Takigawa, T.; Abe, M.; Kawai, T.; Endo, Y.; Yasugi, T.; Endo, G.; Ogino, K. Determination of formaldehyde in urine by headspace gas chromatography. Bull. Environ. Contam. Toxicol. 2007, 79, 1-4. [CrossRef]

4. Liu, J.F.; Peng, J.F.; Chi, Y.G.; Jiang, G.B. Determination of formaldehyde in shiitake mushroom by ionic liquid-based liquid-phase microextraction coupled with liquid chromatography. Talanta 2005, 65, 705-709. [CrossRef]

5. Zhang, Z.M.; Zhao, C.; Ma, Y.J.; Li, G.K. Rapid analysis of trace volatile formaldehyde in aquatic products by derivatization reaction-based surface enhanced Raman spectroscopy. Analyst 2014, 139, 3614-3621. [CrossRef] [PubMed]

6. Kato, S.; Burke, P.J.; Koch, T.H.; Bierbaum, V.M. Formaldehyde in human cancer cells: Detection by preconcentration-chemical ionization mass spectrometry. Anal. Chem. 2001, 73, 2992-2997. [CrossRef]

7. Xu, Z.Q.; Chen, J.H.; Hu, L.L.; Tan, Y.; Liu, S.H.; Yin, J. Recent advances in formaldehyde-responsive fluorescent probes. Chin. Chem. Lett. 2017, 28, 1935-1942. [CrossRef]

8. Ma, Q.; Cui, H.L.; Su, X.G. Highly sensitive gaseous formaldehyde sensor with CdTe quantum dots multilayer films. Biosens. Bioelectron. 2009, 25, 839-844. [CrossRef] [PubMed]

9. Xia, H.; Hu, J.; Tang, J.; Xu, K.L.; Hou, X.D.; Wu, P. A RGB-Type Quantum Dot-based Sensor Array for Sensitive Visual Detection of Trace Formaldehyde in Air. Sci. Rep. 2016, 6, 9. [CrossRef]

10. Cheng, H.R.; Zou, L.W.; Yang, L.; Wang, Z.G.; Lu, X.J. A Turn-on Fluorescence Probe for Rapid, Sensitive and Visual Detection of Formaldehyde. Chemistryselect 2019, 4, 432-436. [CrossRef]

11. Dong, B.L.; Song, X.Z.; Tang, Y.H.; Lin, W.Y. A rapid and facile fluorimetric method for detecting formaldehyde. Sens. Actuators $B$ Chem. 2016, 222, 325-330. [CrossRef]

12. Song, H.; Rajendiran, S.; Kim, N.; Jeong, S.K.; Koo, E.; Park, G.; Thangadurai, T.D.; Yoon, S. A tailor designed fluorescent 'turn-on' sensor of formaldehyde based on the BODIPY motif. Tetrahedron Lett. 2012, 53, 4913-4916. [CrossRef] 
13. Tang, Y.H.; Kong, X.Q.; Xu, A.; Dong, B.L.; Lin, W.Y. Development of a Two-Photon Fluorescent Probe for Imaging of Endogenous Formaldehyde in Living Tissues. Angew. Chem. Int. Edit. 2016, 55, 3356-3359. [CrossRef] [PubMed]

14. Xu, A.; Tang, Y.H.; Lin, W.Y. Development of a mitochondrial-targeted two-photon fluorescence turn-on probe for formaldehyde and its bio-imaging applications in living cells and tissues. N. J. Chem. 2018, 42, 8325-8329. [CrossRef]

15. He, L.W.; Yang, X.L.; Liu, Y.; Kong, X.Q.; Lin, W.Y. A ratiometric fluorescent formaldehyde probe for bioimaging applications. Chem. Commun. 2016, 52, 4029-4032. [CrossRef] [PubMed]

16. Li, J.B.; Wang, Q.Q.; Yuan, L.; Wu, Y.X.; Hu, X.X.; Zhang, X.B.; Tan, W.H. A two-photon fluorescent probe for bio-imaging of formaldehyde in living cells and tissues. Analyst 2016, 141, 3395-3402. [CrossRef] [PubMed]

17. Li, Z.; Xu, Y.Q.; Zhu, H.L.; Qian, Y. Imaging of formaldehyde in plants with a ratiometric fluorescent probe. Chem. Sci. 2017, 8, 5616-5621. [CrossRef]

18. Xu, J.C.; Zhang, Y.; Zeng, L.T.; Liu, J.B.; Kinsella, J.M.; Sheng, R.L. A simple naphthalene-based fluorescent probe for high selective detection of formaldehyde in toffees and HeLa cells via aza-Cope reaction. Talanta 2016, 160, 645-652. [CrossRef]

19. Ding, H.Y.; Yuan, G.Q.; Peng, L.P.; Zhou, L.Y.; Lin, Q.L. TP-FRET-Based Fluorescent Sensor for Ratiometric Detection of Formaldehyde in Real Food Samples, Living Cells, Tissues, and Zebrafish. J. Agric. Food Chem. 2020, 68, 3670-3677. [CrossRef]

20. Li, P.; Zhang, D.; Zhang, Y.C.; Lu, W.; Wang, W.Q.; Chen, T. Ultrafast and Efficient Detection of Formaldehyde in Aqueous Solutions Using Chitosan-based Fluorescent Polymers. ACS Sens 2018, 3, 2394-2401. [CrossRef]

21. Zhou, W.; Dong, H.; Yan, H.; Shi, C.X.; Yu, M.M.; Wei, L.H.; Li, Z.X. HCHO-reactive molecule with dual-emission-enhancement property for quantitatively detecting HCHO in near 100\% water solution. Sens. Actuators B Chem. 2015, 209, 664-669. [CrossRef]

22. Shen, J.H.; Zhu, Y.H.; Yang, X.L.; Li, C.Z. Graphene quantum dots: Emergent nanolights for bioimaging, sensors, catalysis and photovoltaic devices. Chem. Commun. 2012, 48, 3686-3699. [CrossRef]

23. Dong, Y.Q.; Shao, J.W.; Chen, C.Q.; Li, H.; Wang, R.X.; Chi, Y.W.; Lin, X.M.; Chen, G.N. Blue luminescent graphene quantum dots and graphene oxide prepared by tuning the carbonization degree of citric acid. Carbon 2012, 50, 4738-4743. [CrossRef]

24. Chen, Q.L.; Wang, C.F.; Chen, S. One-step synthesis of yellow-emitting carbogenic dots toward white light-emitting diodes. J. Mater. Sci. 2013, 48, 2352-2357. [CrossRef]

25. Zhang, Y.P.; Ma, J.M.; Yang, Y.S.; Ru, J.X.; Liu, X.Y.; Ma, Y.; Guo, H.C. Synthesis of nitrogen-doped graphene quantum dots (N-GQDs) from marigold for detection of $\mathrm{Fe}^{3+}{ }^{3+}$ ) ion and bioimaging. Spectrochim. Acta A Mol. Biomol. Spectrosc. 2019, $217,60-67$. [CrossRef] [PubMed]

26. Zhu, H.; Wang, X.L.; Li, Y.L.; Wang, Z.J.; Yang, F.; Yang, X.R. Microwave synthesis of fluorescent carbon nanoparticles with electrochemiluminescence properties. Chem. Commun. 2009, 5118-5120. [CrossRef]

27. Puvvada, N.; Kumar, B.N.P.; Konar, S.; Kalita, H.; Mandal, M.; Pathak, A. Synthesis of biocompatible multicolor luminescent carbon dots for bioimaging applications. Sci. Technol. Ad. Mater. 2012, 13. [CrossRef] [PubMed]

28. Tang, L.B.; Ji, R.B.; Cao, X.K.; Lin, J.Y.; Jiang, H.X.; Li, X.M.; Teng, K.S.; Luk, C.M.; Zeng, S.J.; Hao, J.H.; et al. Deep Ultraviolet Photoluminescence of Water-Soluble Self-Passivated Graphene Quantum Dots. ACS Nano 2012, 6, 5102-5110. [CrossRef] [PubMed]

29. Qu, D.; Zheng, M.; Zhang, L.G.; Zhao, H.F.; Xie, Z.G.; Jing, X.B.; Haddad, R.E.; Fan, H.Y.; Sun, Z.C. Formation mechanism and optimization of highly luminescent N-doped graphene quantum dots. Sci. Rep. 2014, 4, 9. [CrossRef]

30. Xu, X.Y.; Ray, R.; Gu, Y.L.; Ploehn, H.J.; Gearheart, L.; Raker, K.; Scrivens, W.A. Electrophoretic analysis and purification of fluorescent single-walled carbon nanotube fragments. J. Am. Chem. Soc. 2004, 126, 12736-12737. [CrossRef] [PubMed]

31. Sun, Y.P.; Zhou, B.; Lin, Y.; Wang, W.; Fernando, K.A.S.; Pathak, P.; Meziani, M.J.; Harruff, B.A.; Wang, X.; Wang, H.F.; et al. Quantum-sized carbon dots for bright and colorful photoluminescence. J. Am. Chem. Soc. 2006, 128, 7756-7757. [CrossRef] [PubMed]

32. Li, X.Y.; Wang, H.Q.; Shimizu, Y.; Pyatenko, A.; Kawaguchi, K.; Koshizaki, N. Preparation of carbon quantum dots with tunable photoluminescence by rapid laser passivation in ordinary organic solvents. Chem. Commun. 2011, 47, 932-934. [CrossRef]

33. Zhou, J.G.; Booker, C.; Li, R.Y.; Zhou, X.T.; Sham, T.K.; Sun, X.L.; Ding, Z.F. An electrochemical avenue to blue luminescent nanocrystals from multiwalled carbon nanotubes (MWCNTs). J. Am. Chem. Soc. 2007, 129, 744-745. [CrossRef]

34. Zhang, M.; Bai, L.L.; Shang, W.H.; Xie, W.J.; Ma, H.; Fu, Y.Y.; Fang, D.C.; Sun, H.; Fan, L.Z.; Han, M.; et al. Facile synthesis of water-soluble, highly fluorescent graphene quantum dots as a robust biological label for stem cells. J. Mater. Chem. 2012, 22, 7461-7467. [CrossRef]

35. Liu, F.; Jang, M.H.; Ha, H.D.; Kim, J.H.; Cho, Y.H.; Seo, T.S. Facile Synthetic Method for Pristine Graphene Quantum Dots and Graphene Oxide Quantum Dots: Origin of Blue and Green Luminescence. Adv. Mater. 2013, 25, 3657-3662. [CrossRef]

36. Li, Y.X.; Huang, H.; Ma, Y.H.; Tong, J. Highly sensitive fluorescent detection of dihydroxybenzene based on graphene quantum dots. Sens. Actuators B Chem. 2014, 205, 227-233. [CrossRef]

37. Zhu, S.Y.; Yan, X.L.; Sun, J.; Zhao, X.E.; Wang, X. A novel and sensitive fluorescent assay for artemisinin with graphene quantum dots based on inner filter effect. Talanta 2019, 200, 163-168. [CrossRef] [PubMed]

38. Liu, H.; Na, W.D.; Liu, Z.P.; Chen, X.Q.; Su, X.G. A novel turn-on fluorescent strategy for sensing ascorbic acid using graphene quantum dots as fluorescent probe. Biosens. Bioelectron. 2017, 92, 229-233. [CrossRef]

39. Fan, L.S.; Hu, Y.W.; Wang, X.; Zhang, L.L.; Li, F.H.; Han, D.X.; Li, Z.G.; Zhang, Q.X.; Wang, Z.X.; Niu, L. Fluorescence resonance energy transfer quenching at the surface of graphene quantum dots for ultrasensitive detection of TNT. Talanta 2012, 101, 192-197. [CrossRef] [PubMed] 
40. Liu, X.T.; Na, W.D.; Liu, H.; Sue, X.G. Fluorescence turn-off-on probe based on polypyrrole/graphene quantum composites for selective and sensitive detection of paracetamol and ascorbic acid. Biosens. Bioelectron. 2017, 98, 222-226. [CrossRef]

41. Wang, G.; He, P.; Xu, A.; Guo, Q.; Li, J.; Wang, Z.; Liu, Z.; Chen, D.; Yang, S.; Ding, G. Promising Fast Energy Transfer System Between Graphene Quantum Dots and the Application in Fluorescent Bioimaging. Langmuir 2019, 35, 760-766. [CrossRef] [PubMed]

42. Flak, D.; Przysiecka, L.; Nowaczyk, G.; Scheibe, B.; Koscinski, M.; Jesionowski, T.; Jurga, S. GQDs-MSNs nanocomposite nanoparticles for simultaneous intracellular drug delivery and fluorescent imaging. J. Nanopart. Res. 2018, 20. [CrossRef] [PubMed]

43. Chen, H.; Wang, Z.Y.; Zong, S.F.; Chen, P.; Zhu, D.; Wu, L.; Cui, Y.P. A graphene quantum dot-based FRET system for nucleartargeted and real-time monitoring of drug delivery. Nanoscale 2015, 7, 15477-15486. [CrossRef]

44. Vatanparast, M.; Shariatinia, Z. Revealing the role of different nitrogen functionalities in the drug delivery performance of graphene quantum dots: A combined density functional theory and molecular dynamics approach. J. Mater. Chem. B 2019, 7 , 6156-6171. [CrossRef]

45. Zhang, H.; Cao, Y.; Zhong, L.; Cao, X.; He, J.; Sun, J.; Lei, W. Fast photogenerated electron transfer in N-GQDs/PTI/ZnO-QDs ternary heterostructured nanosheets for photocatalytic $\mathrm{H}_{2}$ evolution under visible light. Appl. Surf. Sci. 2019, 485, 361-367. [CrossRef]

46. Niazi, Z.; Goharshadi, E.K.; Mashreghi, M.; Jorabchi, M.N. Highly efficient solar photocatalytic degradation of a textile dye by TiO2/graphene quantum dots nanocomposite. Photochem. Photobiol. Sci. 2021, 20, 87-99. [CrossRef]

47. Riaz, R.; Ali, M.; Sahito, I.A.; Arbab, A.A.; Maiyalagan, T.; Anjum, A.S.; Ko, M.J.; Jeong, S.H. Self-assembled nitrogen-doped graphene quantum dots (N-GQDs) over graphene sheets for superb electro-photocatalytic activity. Appl. Surf. Sci. 2019, 480, 1035-1046. [CrossRef]

48. Saenwong, K.; Nuengmatcha, P.; Sricharoen, P.; Limchoowong, N.; Chanthai, S. GSH-doped GQDs using citric acid rich-lime oil extract for highly selective and sensitive determination and discrimination of $\mathrm{Fe}^{3+}$ and $\mathrm{Fe}^{2+}$ in the presence of $\mathrm{H}_{2} \mathrm{O}_{2}$ by a fluorescence "turn-off" sensor. RSC Adv. 2018, 8, 10148-10157. [CrossRef]

49. Wang, C.X.; Sun, Y.Y.; Jin, J.L.; Xiong, Z.Y.; Li, D.; Yao, J.R.; Liu, Y.Q. Highly selective, rapid-functioning and sensitive fluorescent test paper based on graphene quantum dots for on-line detection of metal ions. Anal. Methods 2018, 10, 1163-1171. [CrossRef]

50. Yang, Y.; Zou, T.; Wang, Z.; Xing, X.; Peng, S.; Zhao, R.; Zhang, X.; Wang, Y. The Fluorescent Quenching Mechanism of N and $\mathrm{S}$ Co-Doped Graphene Quantum Dots with $\mathrm{Fe}\left({ }^{3+}\right)$ and $\mathrm{Hg}\left({ }^{2+}\right)$ Ions and Their Application as a Novel Fluorescent Sensor. Nanomaterials 2019, 9, 738. [CrossRef]

51. Chakraborti, H.; Sinha, S.; Ghosh, S.; Pal, S.K. Interfacing water soluble nanomaterials with fluorescence chemosensing: Graphene quantum dot to detect $\mathrm{Hg}^{2+}$ in $100 \%$ aqueous solution. Mater. Lett. 2013, 97, 78-80. [CrossRef]

52. Gu, S.Y.; Hsieh, C.T.; Tsai, Y.Y.; Gandomi, Y.A.; Yeom, S.; Kihm, K.D.; Fu, C.C.; Juang, R.S. Sulfur and Nitrogen Co-Doped Graphene Quantum Dots as a Fluorescent Quenching Probe for Highly Sensitive Detection toward Mercury Ions. ACS Appl. Nano Mater. 2019, 2, 790-798. [CrossRef]

53. Liu, J.J.; Zhang, X.L.; Cong, Z.X.; Chen, Z.T.; Yang, H.H.; Chen, G.N. Glutathione-functionalized graphene quantum dots as selective fluorescent probes for phosphate-containing metabolites. Nanoscale 2013, 5, 1810-1815. [CrossRef] [PubMed]

54. Liu, J.J.; Chen, Z.T.; Tang, D.S.; Wang, Y.B.; Kang, L.T.; Yao, J.N. Graphene quantum dots-based fluorescent probe for turn-on sensing of ascorbic acid. Sens. Actuators B Chem. 2015, 212, 214-219. [CrossRef]

55. Qiang, R.B.; Hu, L.F.; Hou, K.M.; Wang, J.Q.; Yang, S.R. Water-Soluble Graphene Quantum Dots as High-Performance Water-Based Lubricant Additive for Steel/Steel Contact. Tribol. Lett. 2019, 67. [CrossRef]

56. Crosby, G.A.; Demas, J.N. Measurement of photoluminescence quantum yields. J. Phys. Chem. 1971, 75, 31. [CrossRef]

57. Tang, L.B.; Ji, R.B.; Li, X.M.; Teng, K.S.; Lau, S.P. Size-Dependent Structural and Optical Characteristics of Glucose-Derived Graphene Quantum Dots. Part. Part. Syst. Charact. 2013, 30, 523-531. [CrossRef]

58. Esteves da Silva, J.C.G.; Gonçalves, H.M.R. Analytical and bioanalytical applications of carbon dots. TrAC Trends Anal. Chem. 2011, 30, 1327-1336. [CrossRef]

59. Zhu, B.C.; Gao, C.C.; Zhao, Y.Z.; Liu, C.Y.; Li, Y.M.; Wei, Q.; Ma, Z.M.; Du, B.; Zhang, X.L. A 4-hydroxynaphthalimide-derived ratiometric fluorescent chemodosimeter for imaging palladium in living cells. Chem. Commun. 2011, 47, 8656-8658. [CrossRef] 